\title{
8
}

\section{Muñecas como yo: volver a pensar las muñecas}

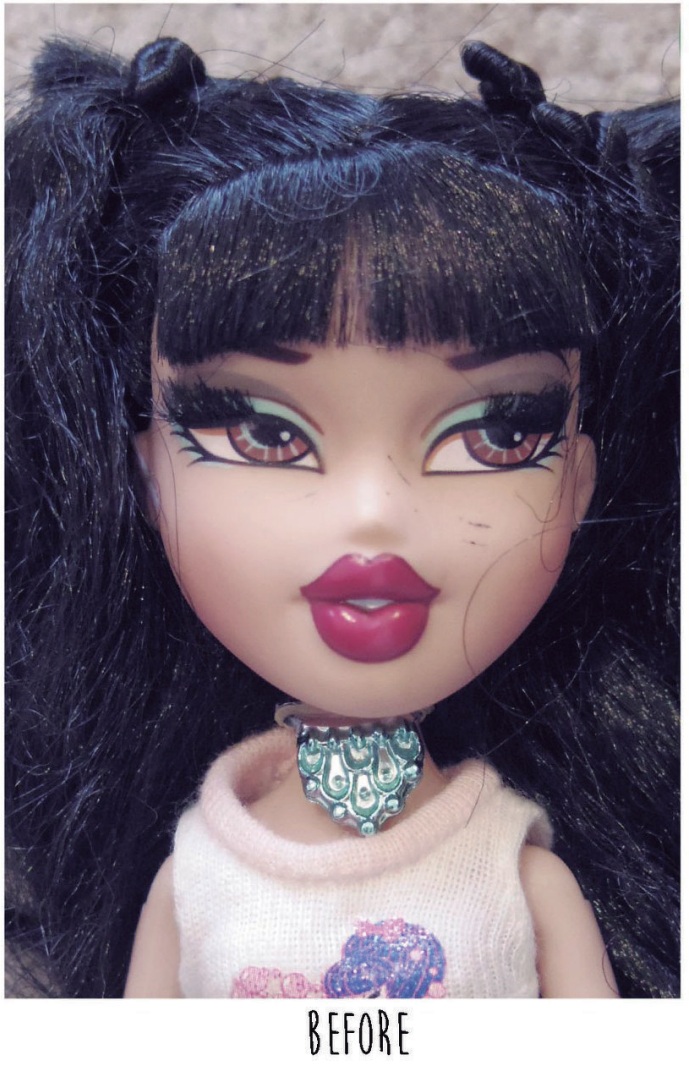

La muñeca es perfecta para el juego simbólico, pero si crecemos con la idea de que los modelos que nos presentan las empresas jugueteras son equivalentes a un ser humano real, estamos construyendo un imaginario falso, limitante y nocivo para la salud física y psíquica. Aquí proponemos un plan de intervención que nos haga conscientes de las iconografías de las muñecas para jugar y de nuestro poder creativo y transformador en relación a los modelos que consumimos.
TREECHANGEDOLLS.COM.AU

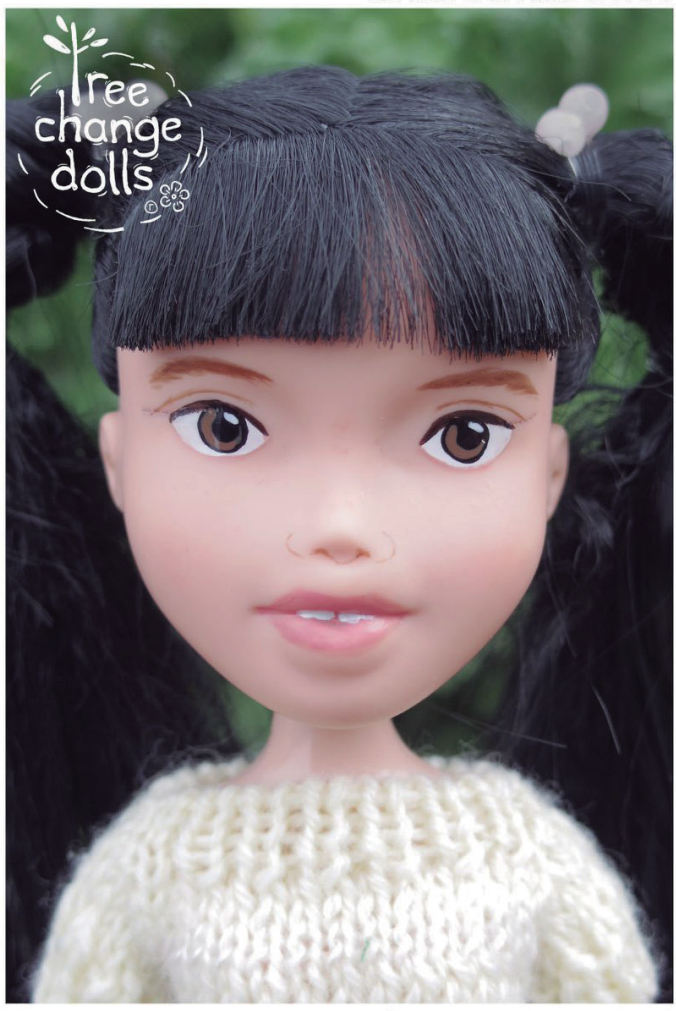

AFTER
Marta

Lage de la Rosa

Universidad Pontificia Comillas mlage@comillas.edu

Pilar Pérez Camarero bandeirapilar@gmail.com 
Vivimos en una sociedad donde lo visual es cada vez más dominante. Sin darnos cuenta convivimos con un montón de imágenes que nos llegan de forma consciente pero también de forma inconsciente. Esto ocurre desde la infancia y los juguetes no escapan a esta realidad.

Nosotras vamos a centrar la atención en las muñecas. Las muñecas han sido un juguete tradicionalmente asociado a las niñas, si bien, en la actualidad se procura una educación igualitaria en cuestión de sexo-género. Las muñecas con las que jugábamos de niñas han evolucionado. Aquellas tampoco eran iguales a las muñecas con las que jugaban nuestras abuelas.

\section{Mundos Barbie}

En la tradición del proceso de aculturación de las niñas, las muñecas han sido utilizadas como un preámbulo de la futura inserción de la niña en el contexto patrimonial que la pretende hecha para el amor y el matrimonio. Hubo a nuestro entender un momento de inflexión en esta historia en el año 1959, cuando Ruth Handler, cofundadora de la empresa Mattel crea la muñeca Barbie.

Aunque ahora nos sorprenda, en su tiempo, la muñeca Barbie representaba un icono de mujer moderna. Ha encarnado a una joven soltera y profesional. Dentro de la imaginería Barbie las múltiples facetas posibles de la muñeca se concentran en su ropa y accesorios generalmente relacionados con profesiones o momentos rituales, en algunos casos empleos típicamente masculinos como: bombera, empresaria, banquera o astronauta.

Todo esto contrasta con las señas identitarias básicas del icono: mujer blanca, rubia, ojos claros y de una delgadez extrema. Proporcionalmente inviable si fuera un ser de carne y hueso por sus medidas anatómicas.

Es cierto que en los últimos tiempos la casa Mattel ha lanzado otros modelos de cuerpos Barbie buscando una normalización de los cánones y los referentes del mundo plural. Estética más redondeada, una Barbie bajita, con la piel oscura, etc.

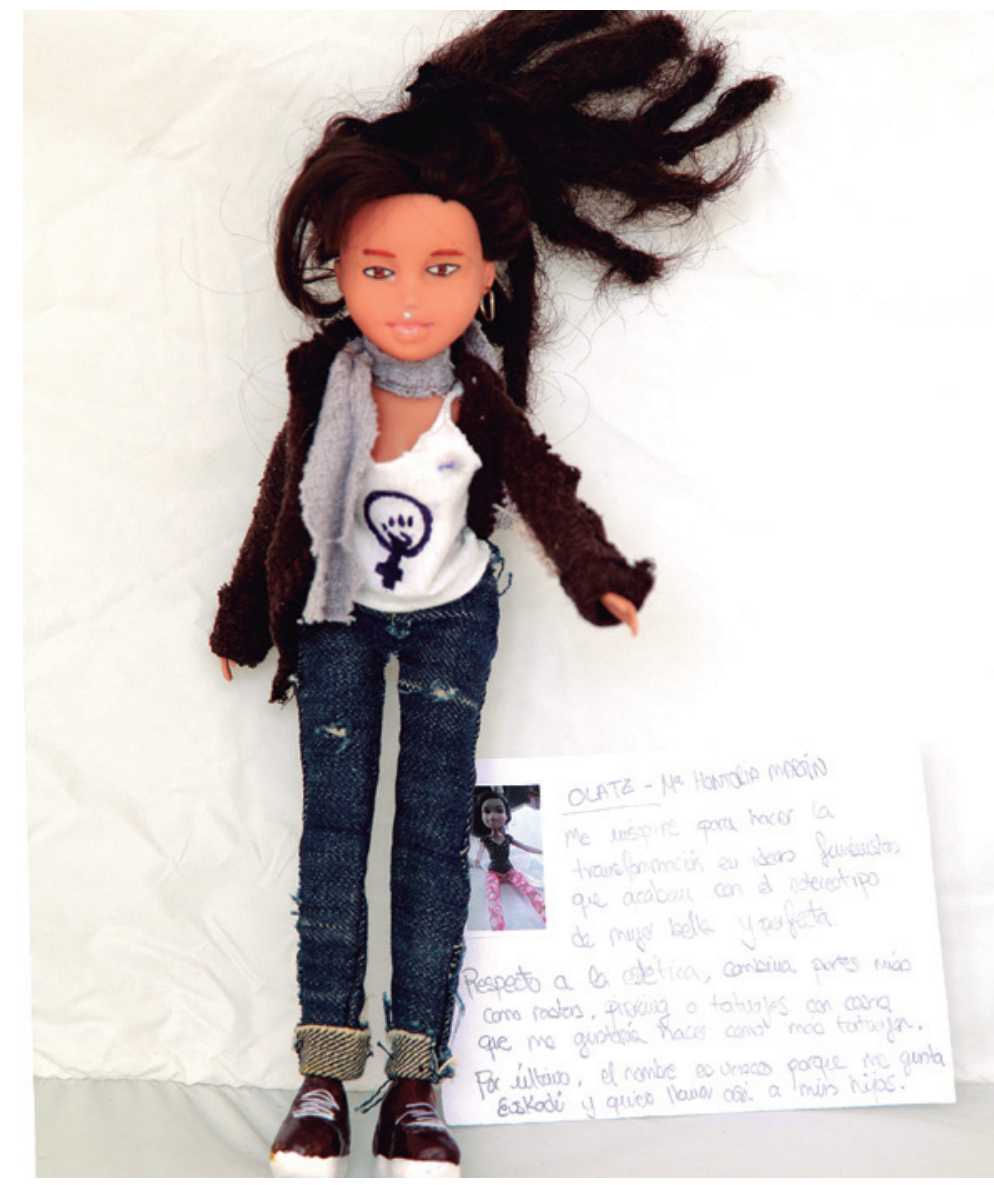

Ahora bien, en nuestra contemporaneidad, estamos en el año 2018, hay una enorme cantidad de muñecas que son consumidas de forma masiva por las niñas y cuyas iconografías exageran la sexualización del cuerpo, el maquillaje y la desproporción, como por ejemplo las muñecas tipo Monster High y las Bratz.

El problema es que estos modelos son interiorizados y las niñas crecen comparándose a esos cánones.

\section{Muñecas y arte en las redes sociales}

En estos últimos años han aparecido artistas que desde su trabajo visual han desarrollado una crítica y una reelaboración de estos estereotipos. Lo encontramos profusamente por internet y en las redes sociales tipo Facebook, Instagram, Twitter...

Nosotras tuvimos noticia de la obra de la artista de Tasmania Sonia Singh, que comenzó a transformar muñecas estereotipadas que compraba en tiendas de segunda mano e intervenía con distintos materiales hasta convertirlas en muñecas próximas a la imagen real de las niñas
Muñeca Olatz creada por la alumna María Hontoria Martín. "Me inspiré para la transformación en ideas feministas que acaban con el estereotipo de mujer bella y perfecta. Respecto a la estética, combina partes mías como rastas, piercing o tatuajes (...). Por último, el nombre es vasco porque me gusta Euskadi y quiero llamar así a mis hijos" 

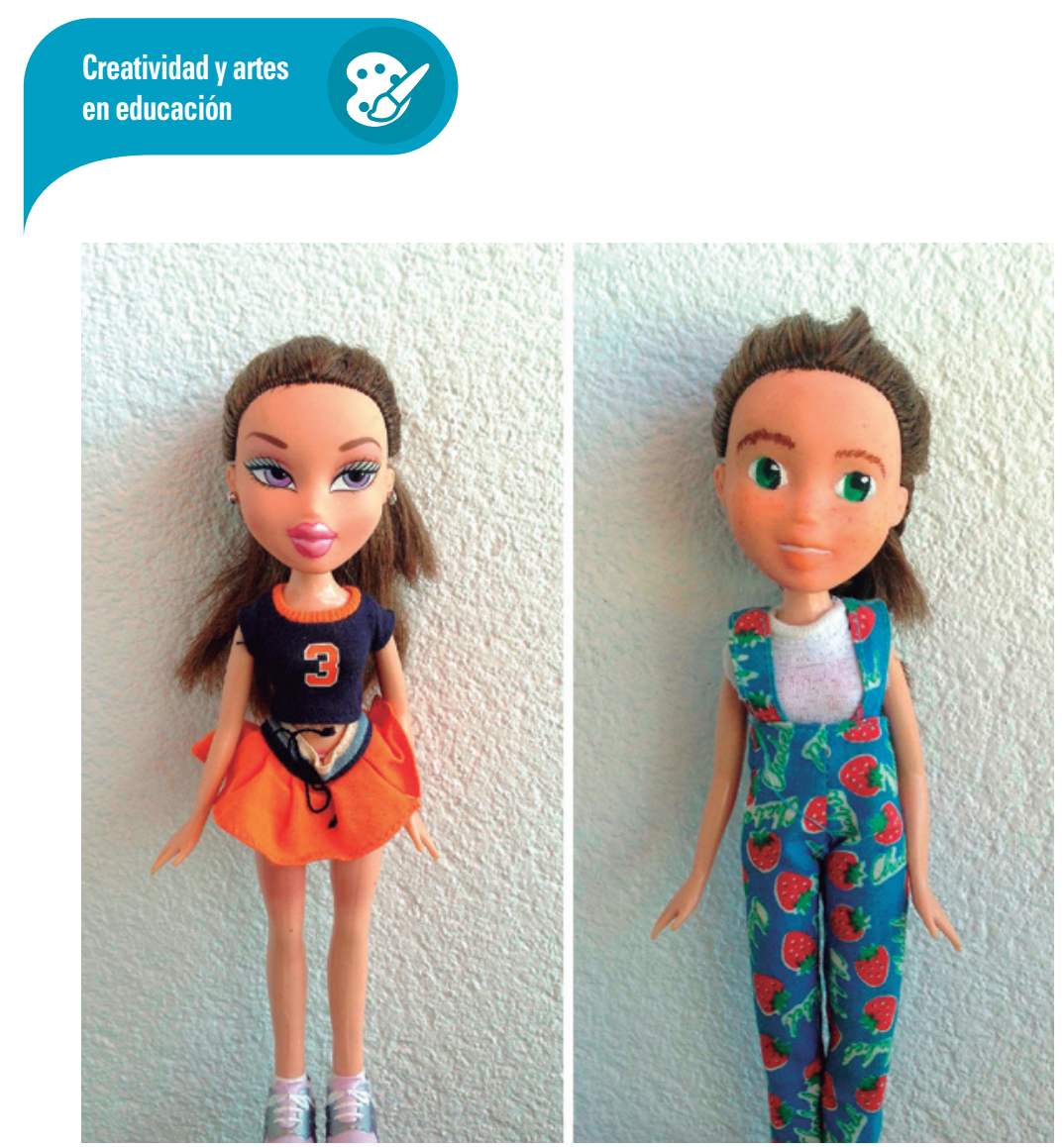

Imagen de antes y después del proceso de transformación de una muñeca por la estudiante de Educación Primaria Cristina Tordesillas que generalmente las consumen o juegan con ellas como se puede ver en la imagen al principio del artículo. Lo primero que hace es borrar los rasgos del rostro extremadamente maquillados y transformar el cabello exageradamente largo, a veces hasta por debajo de las rodillas. También solucionar la anormalidad de los pies que suelen estar prediseñados forzando la horma natural de un pie para llevar tacones muy altos. $O$ emplear distintas pastas para nivelar el busto y las caderas exageradas o desproporcionadas.

La fotógrafa canadiense Dina Goldstein dedica una de sus series la llamada In the Dollhouse o En la Casa de Muñecas (2012) a la vida imperfecta de Barbie, en la que se descubre que Barbie y Kent viven juntos, pero él manifiesta gustos extremadamente femeninos, tacones, lee revistas del corazón, etc., haciendo entrever una orientación distinta a la heterosexual.

A la vista de lo poderoso que puede ser un icono arquetípico, como es una muñeca, y las posibilidades de transformación simbólica que se despliegan desde el arte contemporáneo, nosotras decidimos llevar a las aulas de educación artística de la Universidad de Formación de Profesorado una propuesta de cambio de las muñecas.

El taller resultó un éxito y los estudiantes respondieron a la propuesta con trabajos a través de los cuales pudimos reflexionar sobre la importancia de estas piezas de la cultura popular cotidiana.

La pauta para las transformaciones fue romper los estereotipos y buscar un artefacto con el que el estudiante se sintiera identificado, dentro de una cierta normalización iconográfica. Es por lo que el catálogo publicado tras la exposición De muñeca estereotipada a gente normal lleva el mismo título. Este catálogo se puede consultar online en el repositorio de Academia. edu https://www.academia.edu/30516684/ De_mu\%C3\%B1eca_estereotipada_a_ gente_normal

\section{Transformando las muñecas}

El trabajo del taller para transformar muñecas se realizó con un grupo mayoritariamente de mujeres. Nosotras pensamos que este tipo de iniciativa se puede llevar a cabo con todo tipo de personas, edades y sexo, aunque tradicionalmente sean las niñas quienes han jugado más con las muñecas.

Se sugiere que de preferencia no se compre la muñeca, sino que se use para su transformación una ya adquirida, con la intención de no fomentar el consumismo y además darle valor al reciclaje.

Las chicas que realizaron la experiencia utilizaron todas muñecas que representaban el cuerpo de una mujer o niña, y los chicos en su mayoría también, fue anecdótica la presencia de muñecos que representaran el cuerpo de un hombre, en ningún caso un niño.

Analizamos con el grupo de estudiantes la iconografía de las muñecas para comprender los estereotipos que contienen y que queremos transformar.

Siguiendo el método empleado por la artista Sonia Singh lo primero es eliminar el maquillaje que -en general es exagerado- del rostro de la muñeca con disolvente para uñas y algodón (suelen ser útiles los bastoncitos de los oídos).

A partir de la idea que cada tallerista (persona que hace el taller) tenga de la transformación a realizar en la muñeca, se interviene el cabello. Hemos comprobado que teñir el cabello originalmente rubio y cortarlo son prácticas usuales en el proce- 
so. Aconsejamos usar tintes estables para facilitar la manipulación posterior, evitando manchar otras zonas de la pieza.

En algunos casos es necesaria la transformación de la anatomía rellenando con plastilina u otras masas moldeables ciertas partes del cuerpo, para normalizarlas, como la cintura, el pecho, los pies, etc.

\section{Vistiendo a las muñecas}

Después llega el tiempo de vestir a las muñecas. Para ello sugerimos que busquen por casa telas que les gusten con las que crear la identidad de su nueva muñeca.

A la artista Sonia Singh la ropa de las muñecas se la hace su madre, como la tradición de confeccionar los conjuntos de las peponas por las mamás, las abuelas, las tías...

Nosotras nos encontramos con que la mayoría de los estudiantes no sabían coser, de hecho, alguna de las ropas fue confeccionada por las madres o novias, también en este caso. Pero no solo los chicos, también había chicas que no se habían aventurado con la aguja nunca.

Es sorprendente y dice mucho de la contemporaneidad el hecho de que no estemos acostumbrados a arreglar la ropa que se nos deshila, la tónica general es renovar cuando empieza a estropearse.

\section{Muñecas como yo}

Al observar el fruto de las transformaciones, vemos, que una amplia mayoría de los productos finales han utilizado como leiv motiv, la idea de autorretrato, es decir, la autora o autor busca que la nueva muñeca se le parezca como una forma de romper estereotipos y hacerlo "más normal", entendiendo la normalidad como un tipo de realismo mimético.

Bien es cierto que observamos cómo la mayoría de las "normalizaciones" utilizan la cola de caballo como peinado, los colores castaños en el pelo y las ropas utilizables por sus creadoras según en qué momentos de la vida cotidiana. Es un hecho que la amplia mayoría de las mujeres llevaban a clase el cabello largo y recogido en una coleta.

\section{caminanoo Juntos}

Sería positivo reflexionar las connotaciones iconográficas y los valores que trasmiten algunos juguetes y valorar qué es lo adecuado para que jueguen nuestras hijas e hijos. Pensamos que es una iniciativa que se puede llevar a cabo en familia.

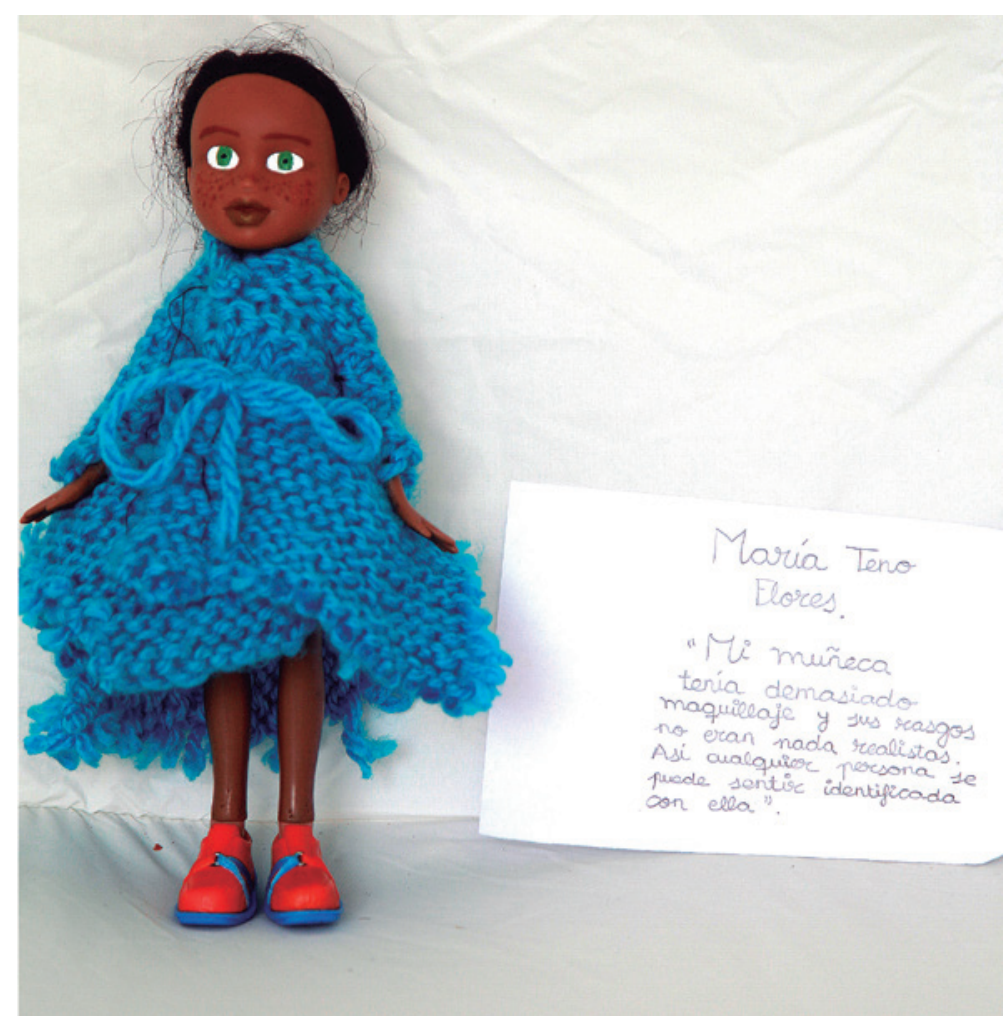

Uno de los resultados iconográficos que más se repitió (dentro de sus variaciones estéticas porque no hubo dos muñecas iguales al terminar y fueron más de 100 en total), fue el tema de las profesiones. Una buena parte representaban a estudiantes como ellas mismas, en esa intención "normalizadora", pero también hubo bomberas, maestras, futbolistas, rockeras...

Otra de las iconografías más recurrente es la indumentaria de ocio.

Aunque algunas muñecas conservan los tacones, una gran mayoría modifica el calzado con tendencia a "hacerlo cómodo".

Hay algún ejemplo más fantasía cuando la vestimenta es para ir de fiesta. Podemos encontrar faldas y vestidos largos o muy cortos y brillos por doquier.

Aunque se desmaquilla a las muñecas en la operación inicial para luego personalizarlas, en algunos casos se pintan
Muñeca trasformada por la alumna María Teno quien en la cartela escribe "Mi muñeca tenía demasiado maquillaje y sus rasgos no eran nada realistas. Ahora cualquier persona se puede sentir identificada con ella" 


\section{IIII. ÁQORA DE PROFESORES}

Dado el carácter interdisciplinar y transversal del arte, una propuesta como esta puede adaptarse a un tipo de trabajo por proyectos que englobe distintas áreas de conocimiento como conocimiento del medio, biología, cuerpo humano, lengua (las cartelas de la exposición se redactan y escriben a mano por sus autores), ética, género e igualdad, filosofía, arte contemporáneo, tecnología, etc.
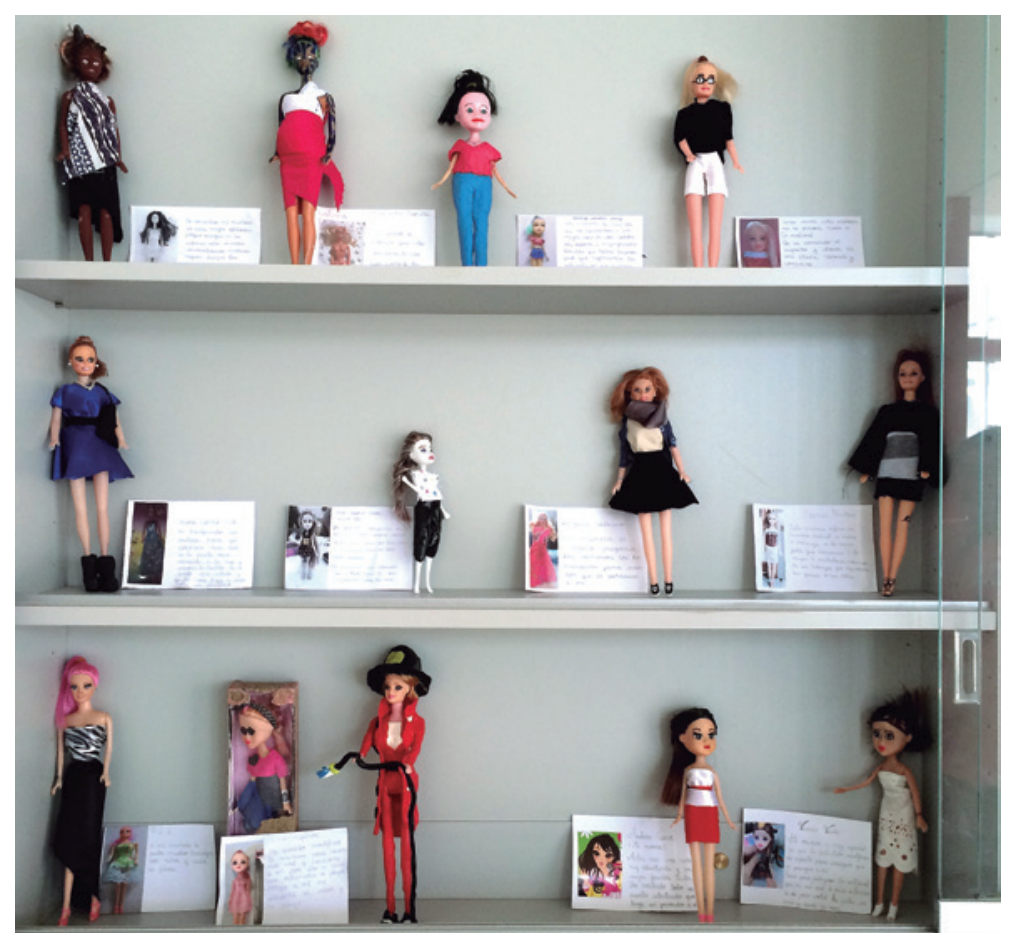

Imagen de una de las vitrinas de la Facultad de Formación de Profesorado de la Universidad Autónoma de Madrid en la que fueron expuestas las muñecas durante más de tres meses las uñas posteriormente, se les pone de nuevo un poco de maquillaje, un lunar y, a veces, hasta tatuajes (en algún caso imitando los que tiene su autora).

En cuestión de edad casi todas las muñecas parten de una creación que como modelo comercial representa a una mujer joven y después de transformada, sigue en el mismo segmento de edad.

\section{Singularidades encontradas}

Aunque la mayoría de las muñecas son inicialmente blancas y siguen siéndolo al final, en algún caso, se pinta la piel para simular la pertenencia a un grupo étnico de piel oscura, es más, con ropas y peinados tribales.

Una chica con rastas construyó su muñeca dotándola de unas rastas muy parecidas a las propias, el resultado fue muy realista en todos sus detalles y constituyó un auténtico autorretrato.
También vemos un caso de muñeca convertida en una geisha, es más, la autora dijo que se trataba de una japonesa que trabajaba en una fábrica durante la Segunda Guerra mundial, con el consiguiente salto histórico.

Una estudiante con vitíligo se inspiró en la modelo que representa una casa comercial para transformar la piel de la muñeca de la misma forma, con la intención de identificarse.

Dos cambios en las muñecas tuvieron como fuente de inspiración el embarazo. En un caso, la autora ya había tenido hijos y se centró en el periodo de gestación de su hija. En el otro no, la estudiante trabajó ese deseo en la pieza que estaba elaborando.

Un par de muñecas rompen con la tónica juvenil, encarnando a dos abuelas, una siguiendo el patrón de anciana arrugada de negro y la segunda, acercándose a una iconografía de hada de cuento, elegante en su edad y a la vez contemporánea respecto a lo que es cumplir años para las mujeres hoy.

Solo dos muñecos representan el cuerpo de un hombre, la modificación la realizaron dos estudiantes varones. Uno decidió representar a un hombre rural con boina, entrado en carnes. El otro también perdió la musculatura del estereotipo inicial, de hecho, lo tituló "Socorrista comilón". En ambos casos la base fue un Geyperman.

\section{Antes de terminar}

La experiencia es lúdica en primer lugar. Facilita la reflexión y el diálogo a partir del modelo de la muñeca estereotipada y, a la vez, nos hace cuestionar los arquetipos que la sociedad de consumo en la que vivimos nos suministra.

Tiene la ventaja de que con nuestras manos podemos modificar algo que no nos gusta y convertirlo en algo único. Fue interesante el testimonio de una alumna, que utilizó una muñeca Barbie de colección que tenía en su casa de cuando era niña y, que cuando acabó el proceso dijo que le gustaba mucho más que antes, y eso que inicialmente había tenido reser- 


\section{Con nuestras manos podemos modificar algo que no nos \\ gusta y convertirlo en algo \\ único}

vas porque eligió esa muñeca para trabajar en el taller, y a la vez estaba muy apegada a ella.

De hecho, la mayoría de las estudiantes manifestaron su predilección por las muñecas transformadas.

Es cierto que cualquier trabajo manual que hagamos sobre un objeto, añade valor al mismo y esto repercute en el sentido emocional hacia aquel, pero también en nuestra propia estima por haber sido capaces y haber realizado algo no repetible, impreso con nuestro sello personal.

La valoración general de los estudiantes fue positiva, disfrutaron de la experiencia y mientras el taller se desarrolló, entraron en el característico fluir que impregna todo lo que es el hacer creativo.

En la creación intervienen distintas fases y hay que superar algunas etapas.

Por ejemplo, es verdad que tuvieron que vencer la reticencia ante algunas dificultades de tipo técnico y ser pacientes a la hora de afrontar la tarea (a veces en el mundo contemporáneo buscamos la in-

\section{DARA SABER MÂS}

Acaso, M. (2006). Esto no son las Torres gemelas. Madrid: La Catarata.

PéRez, P., y Lage, M. (2017). De muñeca estereotipada a gente normal. Madrid: Universidad Autónoma de Madrid.

Steinberg, S., y Kincheloe, J. (2000). Cultura infantil y multinacionales. Madrid: Morata.

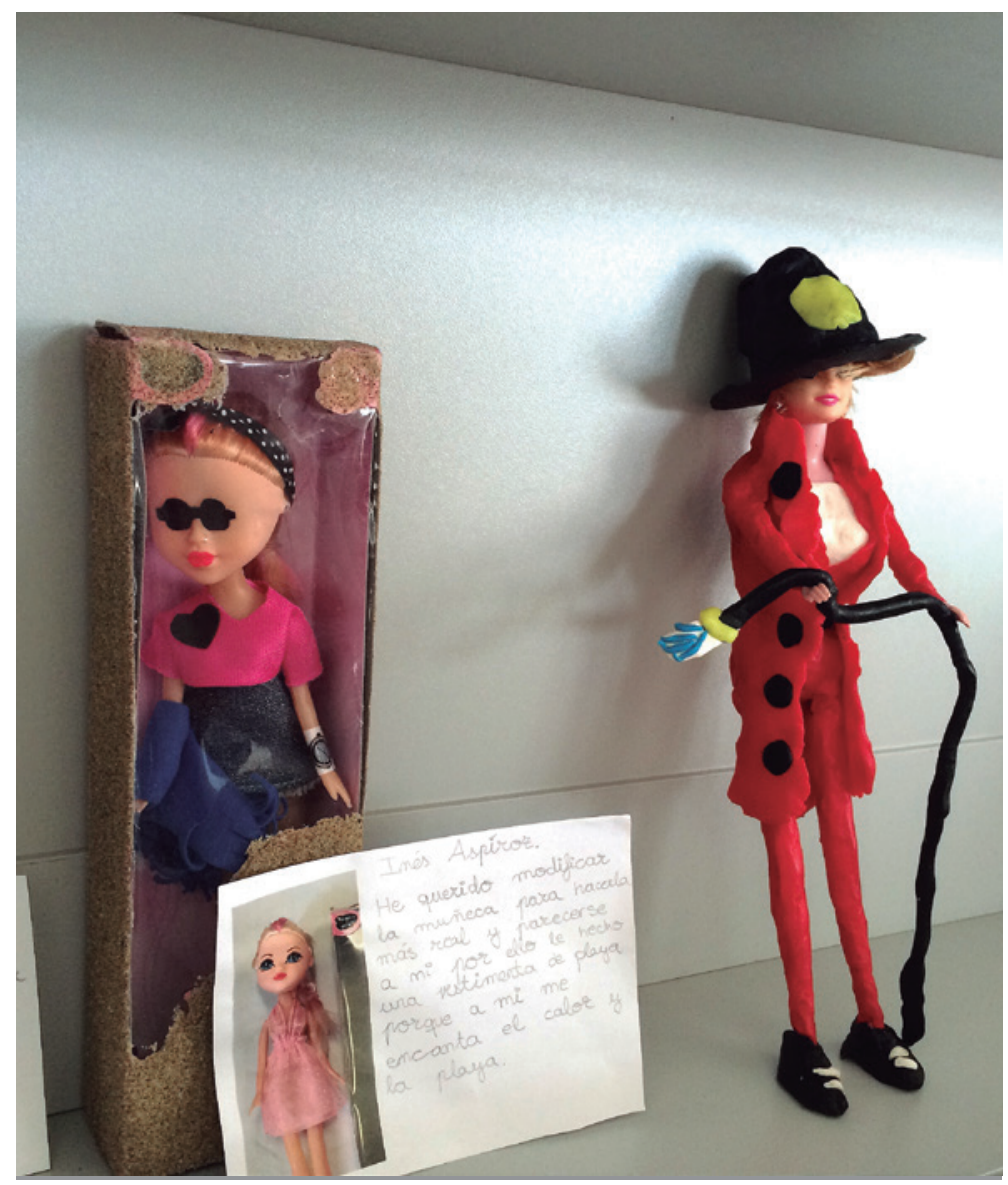

mediatez y esta experiencia se desarrolló a lo largo de varias sesiones).

Si bien no es imprescindible, nosotras terminamos la experiencia realizando una exposición pública de las muñecas. Que tuvo dos repercusiones directas, por una parte, la satisfacción personal de los autores al ver su trabajo expuesto y, por otra parte, la posibilidad de producir reflexión crítica en los espectadores quienes tuvieron ocasión de disfrutar de la exposición suscitando muchos comentarios e incluso la prórroga de la muestra. Fruto de la misma es el catálogo antes mencionado •

\section{HEMOS HABLADO DE}

\section{Educación artística; juego educativo; género; construcción de modelos; cultura popular.}

Este artículo fue solicitado por PADRES Y MAESTROS en marzo de 2018, revisado y aceptado en junio de 2018.
Detalle de una vitrina con dos muñecas la primera empezando por la izquierda

transformada por Inés Aspiroz quien ha querido modificar la muñeca para hacerla más real "y parecerse a mí, me encanta el calor y la playa" y la segunda de Ángel de Castro quien ha vestido a la muñeca de bombera 